\title{
DREADDs: The Power of the Lock, the Weakness of the Key. Favoring the Pursuit of Specific Conditions Rather than Specific Ligands
}

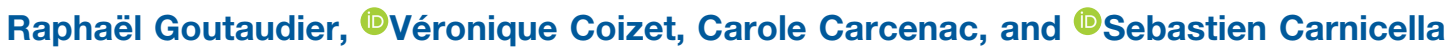

https://doi.org/10.1523/ENEURO.0171-19.2019

Grenoble Institut Des Neurosciences, Institut National de la Santé et de la Recherche Médicale, U1216, Université Grenoble Alpes, 38000 Grenoble, France

\section{Visual Abstract}

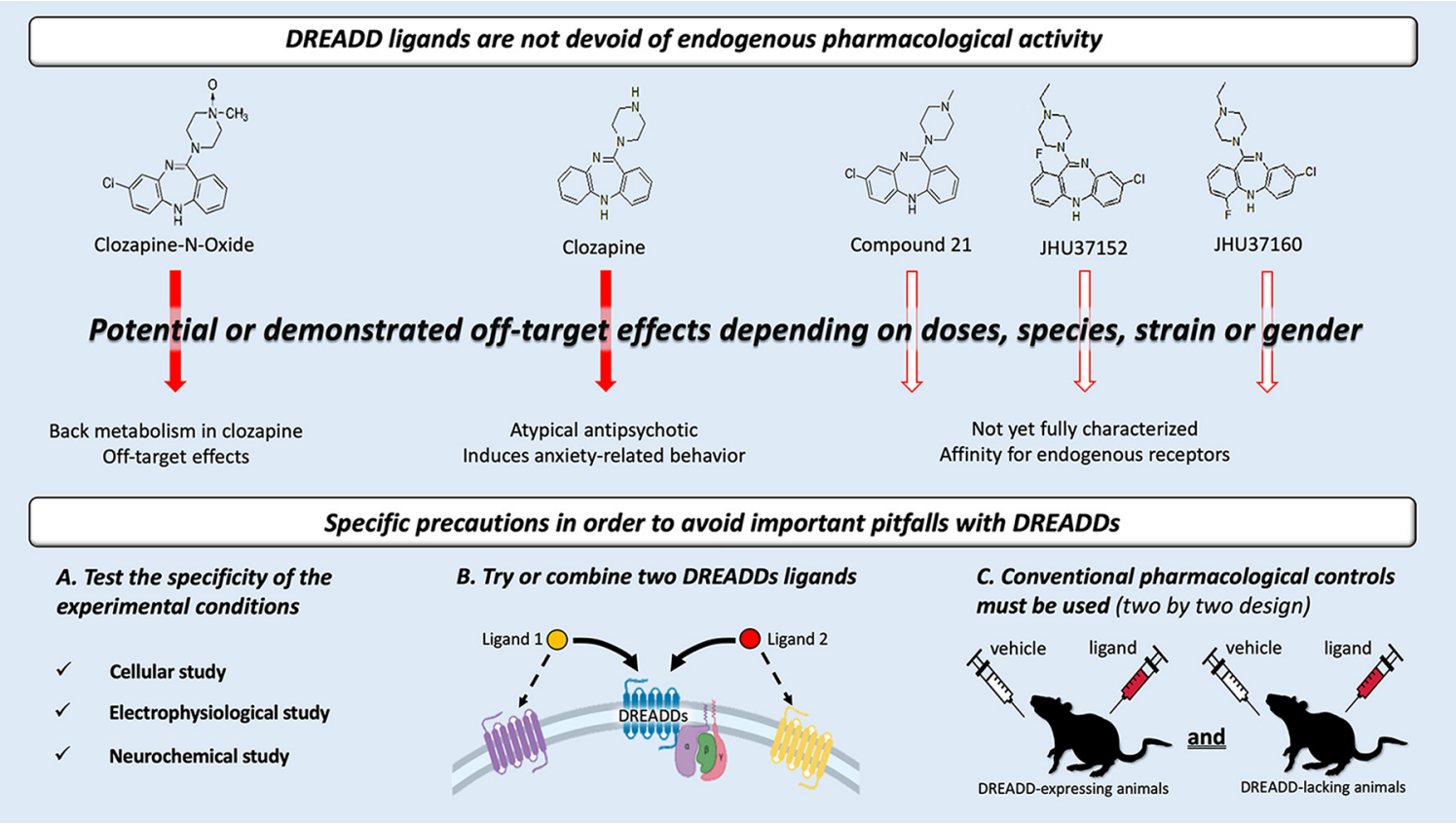

Key words: behavior; C21; clozapine; CNO; DREADDs; electrophysiology

\section{Significance Statement}

DREADDs (designer receptors exclusively activated by designer drugs) are a powerful and tremendous new technique for selectively manipulating a specific neuronal (or non-neuronal) subpopulation. Recent studies indicate, however, that ligands used for DREADDs, such as clozapine- $N$-oxide or its parent compound clozapine, are not as selective as expected, even at reasonable concentrations. Although the new generation of ligands specifically developed for DREADDs or alternative chemogenetic receptors may present some improvements, the absence of potential off-target effects remains to be fully demonstrated. Together, indications from the recent literature on DREADDs should warn current and future users about some weaknesses of this expanding technique in the field of integrative neuroscience and encourage them to take some specific precautions to avoid important pitfalls with DREADDs, which remain a promising and complementary approach to optogenetics with the relevant controls. 
Over the past decade, chemogenetic and optogenetic techniques have revolutionized integrative neuroscience by providing new tools to reversibly manipulate the activity of specific populations or neurotransmitter systems with greater selectivity (Sternson and Roth, 2014; Roth, 2016; Wiegert et al., 2017). Compared with optogenetics, which allow fast and phasic neuronal modulation with high temporal resolution, chemogenetics allow more extended modulation of systems, which is particularly useful for studies focusing on tonic phenomena (e.g., investigation of the implication of dopamine in motivational processes; Whissell et al., 2016). Among chemogenetic tools, designer receptors exclusively activated by designer drugs (DREADDs) are widely used and are referred to as a biological "lock-and-key" system for selective manipulation of cell activity through G-protein signaling pathways. First developed very elegantly by the Roth's group (Armbruster et al., 2007), this G-protein-coupled receptor (GPCR) is a muscarinic receptor: the lock, which was mutated to respond only to clozapine- $N$-oxide (CNO), the key, a derived metabolite of the atypical antipsychotic clozapine, otherwise with, potentially, no pharmacological activity.

However, since 2016, some publications have raised worrying issues concerning the use of CNO. First, relatively high doses of CNO $(10 \mathrm{mg} / \mathrm{kg})$ administered systemically can have pharmacological off-target activity, as evidenced by the induction of behavioral effects in rats and mice not mediated by DREADDs (MacLaren et al., 2016; Gomez et al., 2017; Baerentzen et al., 2019). In addition, Gomez et al. (2017) showed that CNO does not readily cross the blood-brain barrier, may exhibit low DREADD binding affinity, and was back-metabolized into clozapine, becoming the real effector of the DREADDs. Based on these striking observations, they suggested the direct use of low doses of clozapine $(0.1 \mathrm{mg} / \mathrm{kg})$ to activate DREADDs instead of CNO. However, using low doses of clozapine instead of large doses of CNO gradually converting to clozapine leads to two major limitations. First, it is not obvious that clozapine, in acute injection or prolonged diffusion, acts on DREADDs in the same way (Mahler and Aston-Jones, 2018). Second, since clozapine is an atypical antipsychotic agent, it has numerous endogenous targets such as serotoninergic, muscarinic, or dopaminergic receptors, with relatively strong

Received May 9, 2019; accepted August 9, 2019; First published September 27, 2019.

The authors declare no competing financial interests.

Author contributions: R.G., V.C., C.C., and S.C. wrote the paper.

This work was supported by the Institut National de la Santé et de la Recherche Médicale, the Agence Nationale de la Recherche (Grant ANR-16CE16-0002, to S.C.), and Université Grenoble Alpes.

Acknowledgments: We thank Fiona Hemming for English corrections, as well as Sabrina Boulet and Elodie Fino for critical reading of the manuscript.

Correspondence should be addressed to Sebastien Carnicella at Sebastien.carnicella@inserm.fr.

https://doi.org/10.1523/ENEURO.0171-19.2019

Copyright ( 2019 Goutaudier et al.

This is an open-access article distributed under the terms of the Creative Commons Attribution 4.0 International license, which permits unrestricted use, distribution and reproduction in any medium provided that the original work is properly attributed. affinities (Meltzer, 1989; Schotte et al., 1993; Brunello et al., 1995; Ashby and Wang, 1996; Armbruster et al., 2007) and are likely to induce off-target effects, even with low doses. Indeed, the $0.1 \mathrm{mg} / \mathrm{kg}$ dose of clozapine recommended for DREADD experiments has been found to significantly increase anxiety-related behavior in mice (Manzaneque et al., 2002) as well as in rats (an effect that we also observed; R. Goutaudier and S. Carnicella, unpublished observations), where clozapine also affects locomotion through potential sedation and impairs cognitive flexibility (llg et al., 2018).

Although the occurrence of these effects may depend on the species, strain, or sex used, and may be very discrete (as not all behavioral dimensions are affected); they have the potential to significantly interfere with the performance of animals in a variety of behavioral tasks. High stress and anxiety can be confounding factors in memory or pain studies, for example (Sousa et al., 2006; Sorge et al., 2014). Moreover, behavior related to drugs of abuse or psychiatric disorders such as schizophrenia, anxiety, or cognitive flexibility can modify the whole phenotype (Floresco et al., 2009; Koob and Schulkin, 2018). Based on these observations, important precautions are needed with clozapine to avoid biased behavioral studies.

Would a new molecule specifically designed for DREADDs be more selective? Compound 21 (C21) is a synthetic DREADD ligand, developed in 2015 (Chen et al., 2015) and partially characterized in vitro as well as in vivo in 2018 (Thompson et al., 2018). Once again, at low doses $(<3 \mathrm{mg} / \mathrm{kg}$ ), it was described to be devoid of behavioral off-target effects and able to alter the behavior of DREADD-expressing animals. This study was strengthened by Jendryka et al. (2019), who conducted pharmacokinetic and pharmacodynamic experiments using mice and C21 (3 mg/kg). They showed that 30 min after C21 administration the concentration of the molecule in the CSF was $>10$ times higher than the estimated $\mathrm{EC}_{50}$ for DREADD activation ([C21] $]_{\mathrm{CSF}}=40 \mathrm{nM}$ and $\mathrm{EC}_{50 \mathrm{DREADDs}}=$ $3 \mathrm{nM}$ ), and without back-metabolization into clozapine. However, the results of a recent BioRxiv preprint study in rats, mice and macaques (Bonaventura et al., 2018) suggest that, although $\mathrm{C} 21$ exhibits a low brain penetrance, a dose of $1 \mathrm{mg} / \mathrm{kg}$ may already modify brain function in wild-type mice. In addition, a weak affinity and occupancy for DREADDs was observed in vitro in rat brain slices, as well as in vivo in mice and macaques in a positron emission tomography study. Based on the same experimental investigation as for $\mathrm{C} 21$, they proposed, as an alternative, two other ligands, JHU37152 and JHU37160, that possess a higher in vivo potency for DREADDs and potentially fewer off-target effects (Bonaventura et al., 2018). Although this new generation of DREADD ligands appears promising, due to their novelty, they are still poorly characterized and remain structurally homologous to clozapine and CNO. Exhaustive characterization in cellular to behavioral investigation will therefore be crucial to exclude the potential pitfalls found for CNO.

An alternative solution for improving the selectivity of chemogenetic approaches would be to use another lock and key combination. As such, the $\kappa$-opioid receptor- 


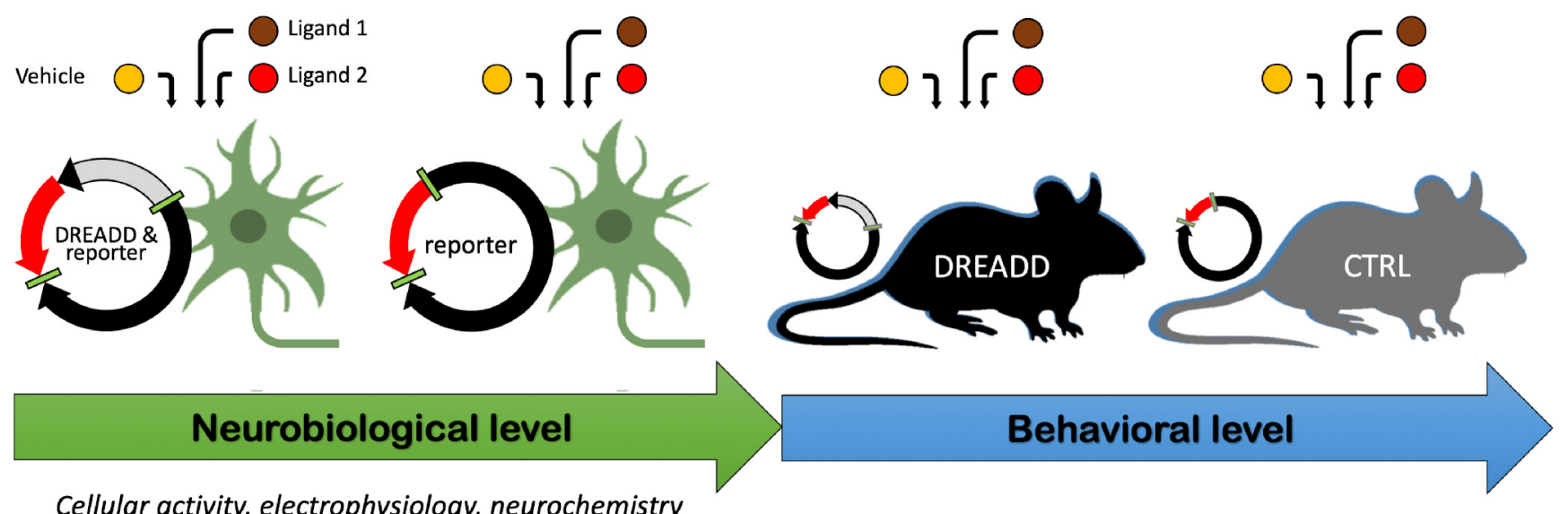

Cellular activity, electrophysiology, neurochemistry

Figure 1. Three steps proposed to validate experimental conditions for DREADD selectivity and efficiency. (1) At a neurobiological level, find the optimal experimental conditions, ligand, and concentration with cellular, electrophysiological, or neurochemical experiments before behavioral investigation. (2) Confirm that an effect is DREADD mediated using two different ligands compared with the vehicle. (3) Do not forget to include DREADD-lacking animals (expressing only the reporter gene) during experiments to verify that the effect, at the chosen dose, is specific to the receptor-ligand interaction.

DREADD (KORD) is a mutated inhibitory GPCR derived from human $\kappa$-opioid receptor (Vardy et al., 2015). Compared with classical DREADDs that bind clozapine, CNO, $\mathrm{C} 21$, or JHU compounds, KORD is engaged by salvinorin $\mathrm{B}$, a drug-like metabolite of the KOR-selective agonist salvinorin A. Although this chemogenetic approach was elegantly used in combination with an activatory DREADD to create an "ON and OFF" system within the same neuronal population (Vardy et al., 2015, Aldrin-Kirk et al., 2016), it remains marginally used because it only reduces the neuronal activity over a short period of time (AldrinKirk and Björklund, 2019). In addition, salvinorin B exhibits some affinity for endogenous KOR at high concentrations and has not yet benefited from in-depth characterization as it is currently performed for DREADD-related compounds (Roth, 2016). Replacing the GPCR by a mutated ion channel, another alternative designed receptor called ligand-gated ion channels (LGICs) is an option developed by the Stenson laboratory (Magnus et al., 2011). Compared with DREADDs, LGICs combine the ligand-binding domain of a mutated nicotinic receptor with the ion pore domain of another chosen receptor to create a chimeric ion channel. Similar to DREADDs, this hybrid channel is activated by a small agonist derived from quinuclidinyl benzamide, an $\alpha 7$ nicotinic acetylcholine receptor agonist, and allows ion exchange across the neuronal membrane. Among other limitations specific to this approach (Aldrin-Kirk and Björklund, 2019), it also shares with DREADDs the use of a pharmacological ligand that can potentially interact with endogenous receptors, depending on the experimental conditions. Finally, all these locks derive from endogenous receptors and, as such, fail to get rid of the limitations intrinsically linked to pharmacology.

Beyond these recent developments and the questions that remain, a crucial question should be asked: will a totally selective and inert key ever be found? Probably not. It is essential to bear in mind that DREADDs are chemogenetic tools combining genetics and pharmacol- ogy. Although genetic approaches offer powerful control of the expression of the locks (i.e., DREADDs) in specific cell populations, or subpopulations with conditional approaches, they derive from endogenous GPCRs and, as such, are subject to the same limits as classical pharmacology for the key. It is therefore unlikely that molecules will be found that will exhibit high binding affinity for DREADDs without affinity for some of the numerous receptors that are already present in the brain and are closely related to DREADDs. For instance, clozapine has a very high affinity for DREADDs, but also for the serotoninergic receptor 5- $\mathrm{HT} 2\left(\mathrm{Ki}=10^{-8}\right.$ for both; Armbruster et al., 2007; Gomez et al., 2017), and a high affinity for a broad range of other GPCRs ( $\mathrm{Ki}=10^{-7}$ to $10^{-6}$; Armbruster et al., 2007). Even synthetic ligands that are specifically designed for this chemogenetic technique exhibit substantial affinities for endogenous receptors. For instance, although JHU37152 and JHU37160 have a lower affinity for 5-HT receptors than clozapine, they have an overall similar target profile to this drug, with an even higher affinity for the muscarinic receptors (Bonaventura et al., 2018), suggesting potentially stronger off-target effects. C21 also exhibits a higher affinity for the histaminergic $\mathrm{H} 1$ receptor than for DREADDs $\left(\mathrm{Ki}>10^{-8}\right.$ and $\mathrm{Ki}$ $=10^{-7.2}$, respectively; Thompson et al., 2018) and a greater binding potential to opioid receptors than clozapine (Bonaventura et al., 2018). To minimize the pitfalls of this powerful approach, regardless of the key choice, critical precautions must be taken (Fig. 1).

First, before any behavioral experiment, the experimental conditions must be tested to find the best ligand and the optimal dose or doses, depending on the experimental approach. DREADDs must not be considered as a turnkey tool; cellular, neurochemical or electrophysiological experiments should be performed before the behavioral study (Mahler et al., 2014; Beloate et al., 2016; Boekhoudt et al., 2016) to confirm the efficacy of the ligand at the chosen dose in the system of interest. In addition, DREADD-lacking control animals must also be 
included to verify the absence of aspecific neurobiological effects of the ligand or the receptor per se that may be activated by a neurotransmitter or have a constitutive activity (Saloman et al., 2016).

Second, when possible, two different DREADD ligands should be tested to confirm that the observed behavioral effects are specifically DREADD mediated. The specific pharmacological actions on DREADDs would be similar, but off-target effects may differ.

Third, and the most critical point, conventional pharmacological controls must be used. The same philosophy as in pharmacology should be applied, and, as for neurobiological experiments, groups of transgenic animals without expressing DREADDs (e.g., DREADDs empty viral vectors) must be integrated to verify the selective effects of the ligand and chosen dose (Smith et al., 2016, Campbell and Marchant, 2018; Mahler and Aston-Jones, 2018; for an example of experimental studies following this design, see also Xia et al., 2017; Cope et al., 2019). This statement may appear trivial, but the pursuit of an absolute selective ligand and the attractiveness of this approach have already led to some overconfident behavioral studies, sometimes conducted in the complete absence of this control.

In conclusion, DREADDs provide a precise way of manipulating neural circuits and behavior, and afford a great alternative to optogenetics to tonically manipulate a specific cellular subpopulation, thus opening exciting new avenues of research. However, just as thermal properties of light in optogenetics can lead to aspecific effects (see also Owen et al., 2019), greater precaution is needed with chemogenetics, and standard controls must be mandatory. DREADD limitations must be recognized and time must be taken to avoid or to control possible off-target effects and to verify that this approach does not induce bias per se. Using the strengths of genetics while paying attention to the weaknesses of pharmacology will maximize the potential of this approach.

\section{References}

Aldrin-Kirk P, Björklund T (2019) Practical considerations for the use of DREADD and other chemogenetic receptors to regulate neuronal activity in the mammalian brain. Methods Mol Biol 1937:59-87.

Aldrin-Kirk P, Heuer A, Wang G, Mattsson B, Lundblad M, Parmar M, Björklund T (2016) DREADD modulation of transplanted DA neurons reveals a novel parkinsonian dyskinesia mechanism mediated by the serotonin 5-HT6 receptor. Neuron 90:955-968.

Armbruster BN, Li X, Pausch MH, Herlitze S, Roth BL (2007) Evolving the lock to fit the key to create a family of $G$ protein-coupled receptors potently activated by an inert ligand. Proc Natl Acad Sci U S A 104:5163-5168.

Ashby CR, Wang RY (1996) Pharmacological actions of the atypical antipsychotic drug clozapine: a review. Synapse 24:349-394.

Baerentzen S, Casado-Sainz A, Lange D, Shalgunov V, Tejada IM, Xiong M, L'Estrade ET, Edgar FG, Lee H, Herth MM, Palner M (2019) The chemogenetic receptor ligand clozapine $\mathrm{N}$-oxide induces in vivo neuroreceptor occupancy and reduces striatal glutamate levels. Front Neurosci 13:187.

Beloate LN, Omrani A, Adan RA, Webb IC, Coolen LM (2016) Ventral tegmental area dopamine cell activation during male rat sexual behavior regulates neuroplasticity and $D$-amphetamine crosssensitization following sex abstinence. J Neurosci 36:9949-9961.
Boekhoudt L, Omrani A, Luijendijk MCM, Wolterink-Donselaar IG, Wijbrans EC, van der Plasse G, Adan RAH (2016) Chemogenetic activation of dopamine neurons in the ventral tegmental area, but not substantia nigra, induces hyperactivity in rats. Eur Neuropsychopharmacol 26:1784-1793.

Bonaventura J, Eldridge MA, Hu F, Gomez JL, Sanchez-Soto M, Abramyan AM, Lam S, Boehm M, Ruiz C, Farrell M, Moreno A, Galal Faress IM, Andersen N, Lin JY, Moaddel R, Morris P, Shi L, Sibley DR, Mahler SV, Nabavi S, et al. (2018) Chemogenetic ligands for translational neurotheranostics. bioRxiv. Advance online publication. December 7, 2018. doi:10.1101/487637.

Brunello N, Masotto C, Steardo L, Markstein R, Racagni G (1995) New insights into the biology of schizophrenia through the mechanism of action of clozapine. Neuropsychopharmacology 13:223234.

Campbell EJ, Marchant NJ (2018) The use of chemogenetics in behavioural neuroscience: receptor variants, targeting approaches and caveats. Br J Pharmacol 175:994-1003.

Chen X, Choo H, Huang XP, Yang X, Stone O, Roth BL, Jin J (2015) The first structure-activity relationship studies for designer receptors exclusively activated by designer drugs. ACS Chem Neurosci 6:476-484.

Cope ZA, Vazey EM, Floresco SB, Aston Jones GS (2019) DREADDmediated modulation of locus coeruleus inputs to mPFC improves strategy set-shifting. Neurobiol Learn Mem 161:1-11.

Floresco SB, Zhang Y, Enomoto T (2009) Neural circuits subserving behavioral flexibility and their relevance to schizophrenia. Behav Brain Res 204:396-409.

Gomez JL, Bonaventura J, Lesniak W, Mathews WB, Sysa-Shah P, Rodriguez LA, Ellis RJ, Richie CT, Harvey BK, Dannals RF, Pomper MG, Bonci A, Michaelides M (2017) Chemogenetics revealed: DREADD occupancy and activation via converted clozapine. Science 357:503-507.

Ilg A-K, Enkel T, Bartsch D, Bähner F (2018) Behavioral effects of acute systemic low-dose clozapine in wild-type rats: implications for the use of DREADDs in behavioral neuroscience. Front Behav Neurosci 12:173.

Jendryka M, Palchaudhuri M, Ursu D, van der Veen B, Liss B, Kätzel D, Nissen W, Pekcec A (2019) Pharmacokinetic and pharmacodynamic actions of clozapine-N-oxide, clozapine, and compound 21 in DREADD-based chemogenetics in mice. Sci Rep 9:1.

Koob GF, Schulkin J (2018) Addiction and stress: an allostatic view. Neurosci Biobehav Rev 106:245-262.

MacLaren DAA, Browne RW, Shaw JK, Krishnan Radhakrishnan S, Khare P, España RA, Clark SD (2016) Clozapine $N$-oxide administration produces behavioral effects in Long-Evans rats: implications for designing DREADD experiments. eNeuro 3:ENEURO.0219-16. 2016.

Magnus CJ, Lee PH, Atasoy D, Su HH, Looger LL, Sternson SM (2011) Chemical and genetic engineering of selective ion channelligand interactions. Science 333:1292-1296.

Mahler SV, Aston-Jones G (2018) CNO evil? Considerations for the use of DREADDs in behavioral neuroscience. Neuropsychopharmacology 43:934-936.

Mahler SV, Vazey EM, Beckley JT, Keistler CR, McGlinchey EM, Kaufling J, Wilson SP, Deisseroth K, Woodward JJ, Aston-Jones G (2014) Designer receptors show role for ventral pallidum input to ventral tegmental area in cocaine seeking. Nat Neurosci 17:577585.

Manzaneque JM, Brain PF, Navarro JF (2002) Effect of low doses of clozapine on behaviour of isolated and group-housed male mice in the elevated plus-maze test. Prog Neuropsychopharmacol Biol Psychiatry 26:349-355.

Meltzer HY (1989) Clinical studies on the mechanism of action of clozapine: the dopamine-serotonin hypothesis of schizophrenia. Psychopharmacology (Berl) 99 [Suppl]:S18-S27.

Owen SF, Liu MH, Kreitzer AC (2019) Thermal constraints on in vivo optogenetic manipulations. Nat Neurosci 22:1061-1065.

Roth BL (2016) DREADDs for neuroscientists. Neuron 89:683-694. 
Saloman JL, Scheff NN, Snyder LM, Ross SE, Davis BM, Gold MS (2016) $\mathrm{G}_{\mathrm{i}}$-DREADD expression in peripheral nerves produces ligand-dependent analgesia, as well as ligand-independent functional changes in sensory neurons. J Neurosci 36:10769-10781.

Schotte A, Janssen PFM, Megens A, Leysen JE (1993) Occupancy of central neurotransmitter receptors by risperidone, clozapine and haloperidol, measured ex vivo by quantitative autoradiography. Brain Res 631:191-202.

Smith KS, Bucci DJ, Luikart BW, Mahler SV (2016) DREADDS: Use and application in behavioral neuroscience. Behav Neurosci 130: 137-55.

Sorge RE, Martin LJ, Isbester KA, Sotocinal SG, Rosen S, Tuttle AH, Wieskopf JS, Acland EL, Dokova A, Kadoura B, Leger P, Mapplebeck JC, McPhail M, Delaney A, Wigerblad G, Schumann AP, Quinn T, Frasnelli J, Svensson Cl, Sternberg WF et al. (2014) Olfactory exposure to males, including men, causes stress and related analgesia in rodents. Nat Methods 11:629-632.

Sousa N, Almeida OFX, Wotjak CT (2006) A hitchhiker's guide to behavioral analysis in laboratory rodents. Genes Brain Behav 5 [Suppl 2]:5-24.

Sternson SM, Roth BL (2014) Chemogenetic tools to interrogate brain functions. Annu Rev Neurosci 37:387-407.
Thompson KJ, Khajehali E, Bradley SJ, Navarrete JS, Huang XP, Slocum S, Jin J, Liu J, Xiong Y, Olsen RHJ, Diberto JF, Boyt KM, Pina MM, Pati D, Molloy C, Bundgaard C, Sexton PM, Kash TL, Krashes MJ, Christopoulos A, et al. (2018) DREADD Agonist 21 is an effective agonist for muscarinic-based DREADDs in vitro and in vivo. ACS Pharmacol Transl Sci 1:61-72.

Vardy E, Robinson JE, Li C, Olsen RHJ, DiBerto JF, Giguere PM, Sassano FM, Huang XP, Zhu H, Urban DJ, White KL, Rittiner JE, Crowley NA, Pleil KE, Mazzone CM, Mosier PD, Song J, Kash TL, Malanga CJ, Krashes MJ, et al. (2015) A New DREADD facilitates the multiplexed chemogenetic interrogation of behavior. Neuron 86:936-946.

Whissell PD, Tohyama S, Martin LJ (2016) The use of DREADDs to deconstruct behavior. Front Genet 7:1-15.

Wiegert JS, Mahn M, Prigge M, Printz Y, Yizhar O (2017) Silencing neurons: tools, applications, and experimental constraints. Neuron 95:504-529.

Xia F, Richards BA, Tran MM, Josselyn SA, Takehara-Nishiuchi K, Frankland PW (2017) Parvalbumin-positive interneurons mediate neocortical-hippocampal interactions that are necessary for memory consolidation. Elife 6:e27868. 